\title{
Identification of Parental Lines and Hybrid using Molecular Techniques in CGMS based Chilli (Capsicum annuum L.) Hybrid UARChH42 (JCH42)
}

\author{
Neha Thakur ${ }^{1}$, S.N. Vasudevan², B.V. Tembhurne ${ }^{3}$, S.R. Doddagoudar ${ }^{3}$
}

10.18805/IJARe.A-5893

\begin{abstract}
Background: Molecular markers are the landmarks on DNA that identifies a particular sequence of base pairs coding for a character. SCAR (Sequenced Characterized Amplified Region) markers are proving to be more effective in identification of genotypes as they are PCR based co-dominant markers. In view of plant variety registration under PPV and FRA, 2001 molecular characterization/ identification of the variety is essential to ascertain the trueness of the variety, hence present studies have been planned and executed.

Methods: In present investigation CGMS based chilli hybrid UARChH42 and its parental lines were identified using molecular techniques. A line, B line, R line and hybrid seedlings were used for DNA extraction and characterized on the basis of polymorphism with respect to sterility or fertility by using SCAR markers.

Result: P1 and P2 and coxll-SCAR which are sterility specific markers could amplify A line and hybrid showing a definite band. CRFSCAR 870 is a fertility specific marker amplified R line and hybrid. Also CMS-SCAR 130 and CMS-SCAR 130/140 were able to identified $A$ line, $B$ line, $R$ line and hybrid. Two of the markers viz. orf-456-SCAR atp6-SCAR and were not able to specify any case of parental lines or hybrid identification. Hybridity of UARChH42 (JCH42) chilli hybrid was determined by any similarity in the banding pattern with any of its parent. This study would help in the fulfillment of the requirements of protection of plant varieties and farmers' rights authority (PPVFRA), New Delhi for registration purpose.
\end{abstract}

Key words: Chilli, CGMS, Hybrid, Molecular markers, SCAR marker.

\section{INTRODUCTION}

Chilli (Capsicum annuum L.) is an important commercial crop of India grown on an area of 364'000 hectare (201819) with a production of 3720 '000 MT and productivity of 10.2 $\mathrm{MT} \mathrm{ha}^{-1}$ Anonymous (2019). It is an often cross pollinated vegetable crop with 7.6 to 36.8 per cent out crossing, Oland and Prorter (1941). Cytoplasmic Male Sterility (CMS) is used as an alternate technique for hand emasculation and pollination for producing large scale $F_{1}$ hybrid seeds in chilli. CMS is a maternally inherited trait which causes the inability of a plant to produce functional pollen. In all documented examples, the male sterilityinducing cytoplasm effect can be counteracted by nuclear genes also called as restorer (s) of fertility (Rf) Budar et al. (2003). CMS has been observed in more than 150 plant species, Schnable and Wise (1998) and CMS determinants are found to be located in the mitochondrial genome. In case of CMS lines environment influences the sterility expression (gene expression) Dhaliwal and Jindal (2014), but it does not alter the gene. The main advantage of CMS system over the NMS (nuclear male sterility) system is that the progeny is 100 per cent male sterile and the efforts in identifying male sterile plants and their removal from the mixed population in the NMS system are suitably excluded. Cytoplasmic genetic male sterility (CGMS) uses restorer lines for production of fertile seeds. This reduces the hybrid
${ }^{1}$ College of Horticulture and Forestry, Thunag-175 048, Mandi, Himachal Pradesh, India.

${ }^{2}$ ZARS, V.C. Farm, Mandya, University of Agricultural Sciences, Bengaluru-571 405, Karnataka, India.

${ }^{3}$ College of Agriculture, University of Agricultural Sciences, Raichur584 104, Karnataka, India.

Corresponding Author: Neha Thakur, College of Horticulture and Forestry, Thunag-175 048, Mandi, Himachal Pradesh, India. Email: nthakur0708@gmail.com

How to cite this article: Thakur, N., Vasudevan, S.N., Tembhurne, B.V. and Doddagoudar, S.R. (2022). Identification of Parental Lines and Hybrid using Molecular Techniques in CGMS based Chilli (Capsicum annuum L.) Hybrid UARChH42 (JCH42). Indian Journal of Agricultural Research. DOI: 10.18805/IJARe.A-5893.

Submitted: 11-08-2021 Accepted: 26-11-2021 Online: 11-01-2022

seed cost by about 50 per cent Aulakh (2016) and ensures purity of the $F_{1}$ seed as there is no chance of selfing.

A variety/ parental/hybrid can be distinguished through a set of morphological and biochemical characteristics, which are helpull in establishing novelity, distinctness, uniformity and stability (NDUS). Further, in view of the fulfillment of the Protection of Plant Varieties and Farmers' Rights Authority (PPVFRA), New Delhi for varietal 
registration purpose, there is a necessity to identify suitable molecular markers for identification of parental lines as well as to determine the hybridity of $F_{1}$ seeds. This will facilitates the Seed Certification Agencies to carry out genetic purity test effectively for quick declaration of results of certified seed lots and to overcome the much delay process through grow out test.

Using molecular techniques for the identification of parental lines and hybrids at seedling stage increases the efficacy for developing male sterile female inbred lines for hybrid seed production. Male sterility systems are widely used to produce cost-effective hybrids and their seeds. Tembhurne et al. (2016) In India, both nuclear GMS and CMS systems have been developed and characterized in chilli and are being used for the development of experimental crosses, potential hybrids and production of hybrid seeds. Among the several types of molecular markers, SCAR (Sequenced Characterized Amplified Region) markers are proved to be effective in identification of genotypes as they are co-dominant and PCR based markers. SCAR marker can distinguish normal $(\mathrm{N})$ from sterile $(\mathrm{S})$ cytoplasm using polymerase chain reaction ( $P C R$ ) analysis. For the purpose of showing recessive or polygenic inheritance traits that are difficult to select directly the technique of molecular markerassisted selection is widely utilized in crop breeding Chen et al. (2010).

SCAR is the genomic DNA fragment at a single genetically defined locus which is identified by PCR (Polymerase Chain Reaction) amplification Paran and Michelmore (1993). The unique nature of marker system is determined by the sequence and spacing of the primer sequences rather than by hybridization Mokate (2009). Keeping in mind the advantages of molecular markers in characterization experiments, present research investigation was planned with the objective to differentiate the parental lines and $F_{1}$ of CMS based chilli hybrid UARChH42 by using SCAR markers.

\section{MATERIALS AND METHODS}

The present investigation was carried out in the molecular laboratory of Main Agricultural Research Station (MARS), University of Agricultural Sciences, Raichur, Karnataka. Chilli hybrid UARChH42 (JCH42) seeds were produced by crossing $A$ and $R$ parental lines. Further seeds of parental lines viz. A line, $B$ line and $R$ line and hybrid were subjected to molecular techniques for their identification and determination of hybridity during 2018.

\section{Molecular technique}

Seedlings were raised from three parental lines and hybrid seed. Seeds were placed for germination in the walk in germinator and leaves taken from two week old seedling were used for the extraction of DNA by $10 \%$ CTAB method and subjected to $0.8 \%$ Agrose gel electrophoresis for checking the quality of DNA. Further, the good quality DNA was used for carrying out Polymerase Chain Reaction (PCR) for the specific SCAR markers viz. P1 and P2, coxll-SCAR marker, CMS-SCAR 130, CMS-SCAR 130/140, CRF-SCAR 870 , orf-456-SCAR and atp6-SCAR. The PCR cycling profile of these markers is presented in Table 1. The multiplicated DNA from PCR was then run in $1.5 \%$ Agrose gel electrophoresis and further banding pattern was observed by gel documentation for presence and absence of band.

\section{RESULT AND DISCUSSION}

Among the seven SCAR markers used to determine the hybridity of chilli hybrid UARChH42 (JCH42) and to identify the parental lines, five markers showed specific bands for sterility or fertility whereas, two of the markers were not able to specify any case of parental lines or hybrid (Table 2). Four markers viz., CMS-SCAR 130, CMS-SCAR 130/140 F, P1 and P2 and cox-II SCAR were specific to cytoplasmic male sterility as they showed bands at respective base pair (Fig 1) in the sterile line (JNA-1) as well as hybrid UARChH42 $(\mathrm{JCH} 42)$ which reveals that JNA-1 is the female parent for the hybrid seed production. So also, two markers CMSSCAR 130/140 R and CRF-SCAR 870 were specific to male fertility as they showed bands at respective base pair in the $\mathrm{R}$ line (BVC-42) as well as hybrid UARChH42 (JCH42) which indicates that BVC-42 is the male parent in hybrid seed production of UARChH42 (JCH42) (Fig 2). Whereas atp6SCAR and orf-456-SCAR markers did not show any specific banding pattern in the present experiment (Fig 2).

The identification of parental lines was done on the basis of presence and absence of CGMS sterile/fertile cytoplasm (A or $B$ line) or restorer gene ( $R$ line). JNA- 1 (A line) was detected by amplifying the DNA with $\mathrm{P} 1$ and $\mathrm{P} 2$ and coxllSCAR marker which are specific to sterile cytoplasm. It was found that by using these markers only $A$ line produced band at 580 and $708 \mathrm{bp}$ respectively among all the parental lines, which confirmed that $A$ line is the sterile line or the female parent in the hybrid seed production. Among the $A$ and $B$ line, CGMS sterile cytoplasm is found in A line and fertile/ normal cytoplasm was found in JNB 1 ( $B$ line) and also in BVC-42 ( $R$ line). It was confirmed by the banding pattern observed in case of CMS-SCAR 130/140 and CMS-SCAR 130 marker (sterile cytoplasm specific marker), wherein $A$ line produced band at $130 \mathrm{bp}$ and $B$ line and $R$ line at 140 $\mathrm{bp}$. Thus, it shows that $\mathrm{B}$ line is the maintainer line in hybrid seed production of UARChH42 (JCH42). CRF-SCAR 870 marker is specific to fertility restoration genes. Using this marker, bands were produced in R line (BVC-42) as well as hybrid at $600 \mathrm{bp}$. This shows that BVC-42 is the male parent in hybrid seed production of UARChH42 (JCH42). These results are in conformity with Lin et al. (2015), Yeh et al. (2016), Tembhurne et al. (2016) and Sun et al. (2017). Two of the markers orf-456-SCAR and atp6-SCAR were unable to identify any parental lines or prove hybridity as it did not produce any specific banding pattern. 


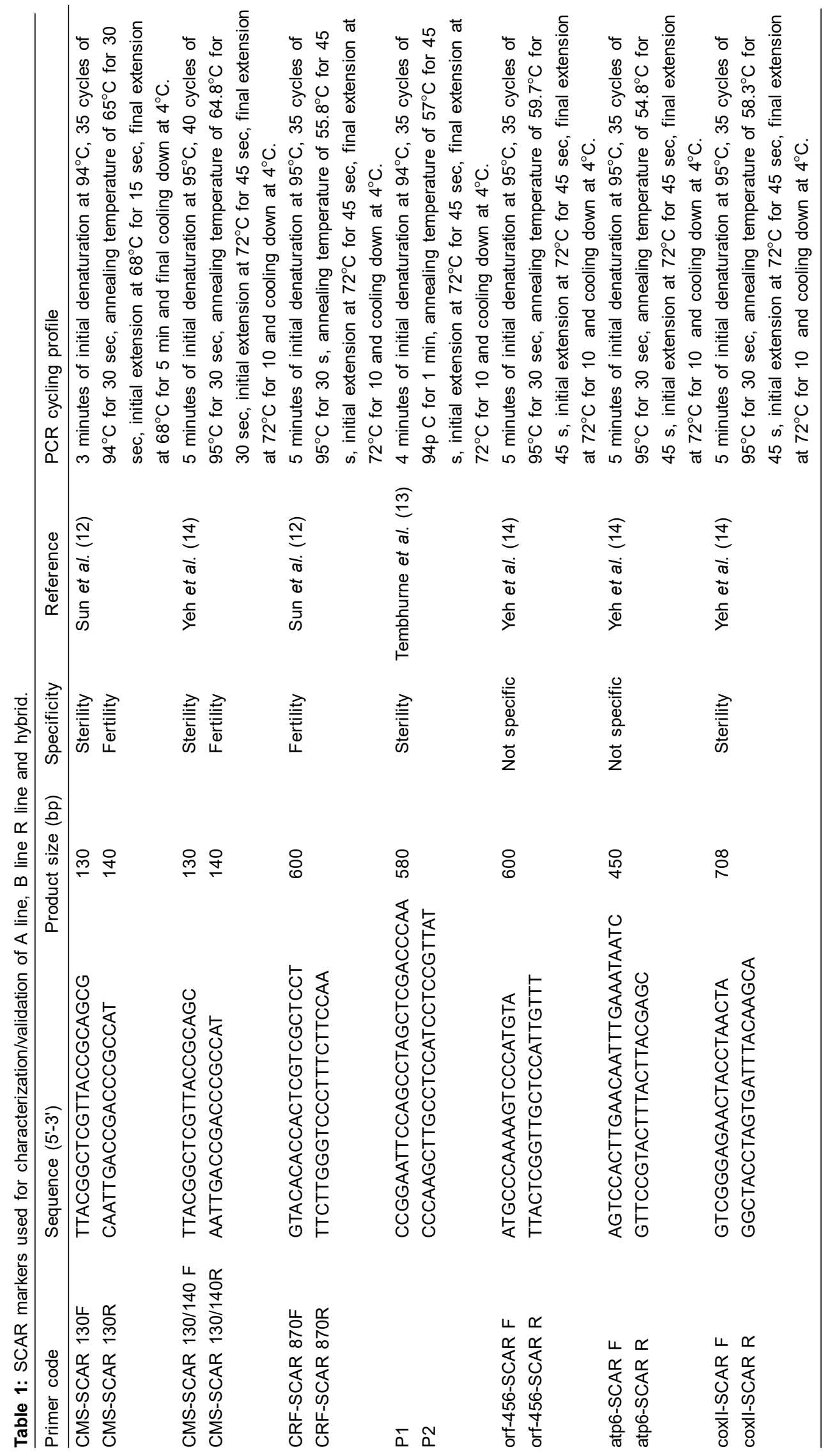


Identification of Parental Lines and Hybrid using Molecular Techniques in CGMS based Chilli (Capsicum annuum L.) Hybrid...

Table 2: Determination of hybridity using specific SCAR markers.

\begin{tabular}{|c|c|c|c|c|c|c|c|}
\hline Primer code & Sequence $\left(5^{\prime}-3^{\prime}\right)$ & Product size $(b p)$ & $\mathrm{A}$ & $\mathrm{B}$ & $\mathrm{H}$ & $\mathrm{R}$ & Specificity \\
\hline CMS-SCAR $130 \mathrm{~F}$ & TTACGGCTCGTTACCGCAGCG & 130 & + & - & + & - & Sterility \\
\hline CMS-SCAR $130 \mathrm{R}$ & CAATTGACCGACCCGCCAT & 140 & - & + & - & + & Fertility \\
\hline CMS-SCAR 130/140 F & TTACGGCTCGTTACCGCAGC & 130 & + & - & + & - & Sterility \\
\hline CMS-SCAR 130/140 R & AATTGACCGACCCGCCAT & 140 & - & + & - & + & Fertility \\
\hline CRF-SCAR $870 \mathrm{~F}$ & GTACACACCACTCGTCGCTCCT & 600 & - & - & + & + & Fertility \\
\hline CRF-SCAR $870 \mathrm{R}$ & TTCTTGGGTCCCTTTCTTCCAA & & & & & & \\
\hline P1 & CCGGAATTCCAGCCTAGCTCGACCCAA & 580 & + & - & + & - & Sterility \\
\hline $\mathrm{P} 2$ & CCCAAGCTTGССTCCATCСTCCGTTAT & & & & & & \\
\hline orf-456-SCAR F & ATGCCCAAAAGTCCCATGTA & 600 & + & + & + & - & Not specific \\
\hline orf-456-SCAR R & TTACTCGGTTGCTCCATTGTTT & & & & & & \\
\hline atp6-SCAR F & AGTCCACTTGAACAATTTGAAATAATC & 450 & + & + & + & - & Not specific \\
\hline atp6-SCAR R & GTTCCGTACTTTACTTACGAGC & & & & & & \\
\hline COxII-SCAR F & GTCGGGAGAACTACCTAACTA & 708 & + & - & + & - & St ${ }^{1}$ erility \\
\hline coxll-SCAR R & GGCTACCTAGTGATTTACAAGCA & & & & & & \\
\hline
\end{tabular}

+ Showed band.

- no band.

A.

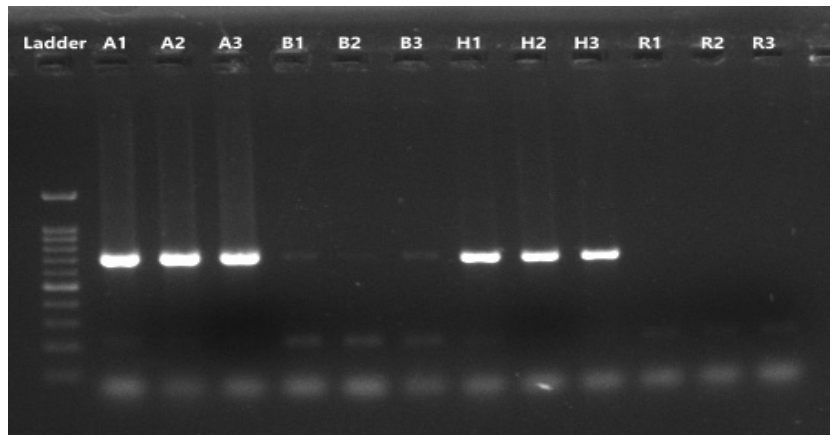

B.

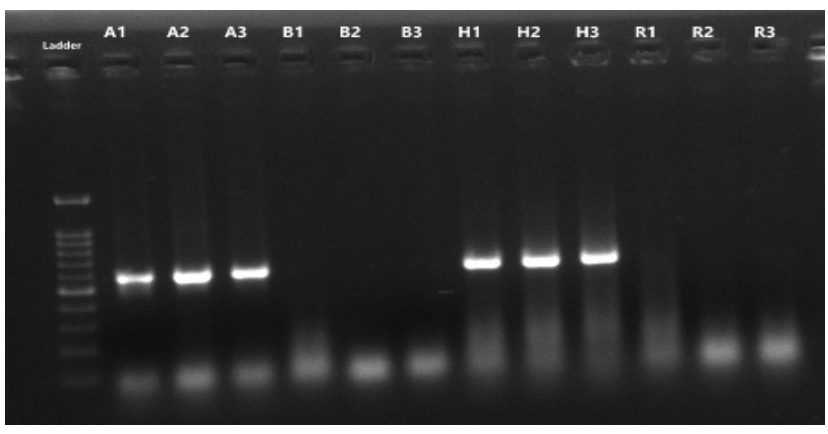

C.

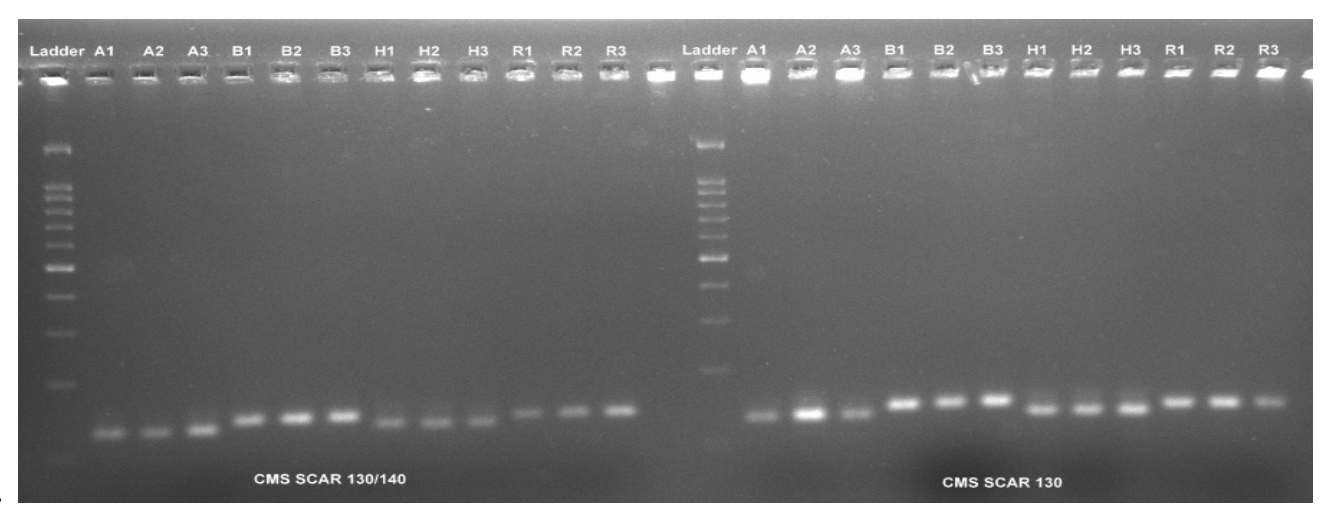

Fig 1: Characterization of parental lines and hybrid using SCAR markers; A. coxll-SCAR at 708 bp, B. P1\&P2 at 580 bp C. CMSSCAR $130 / 140$ at 140 bp and D. CMS-SCAR 130 at 130 bp. A line=A1 to A3, B line=B1 to B3, Hybrid =H1 to H3 and R line =R1 to R3, Ladder $=100 \mathrm{bp}$ 


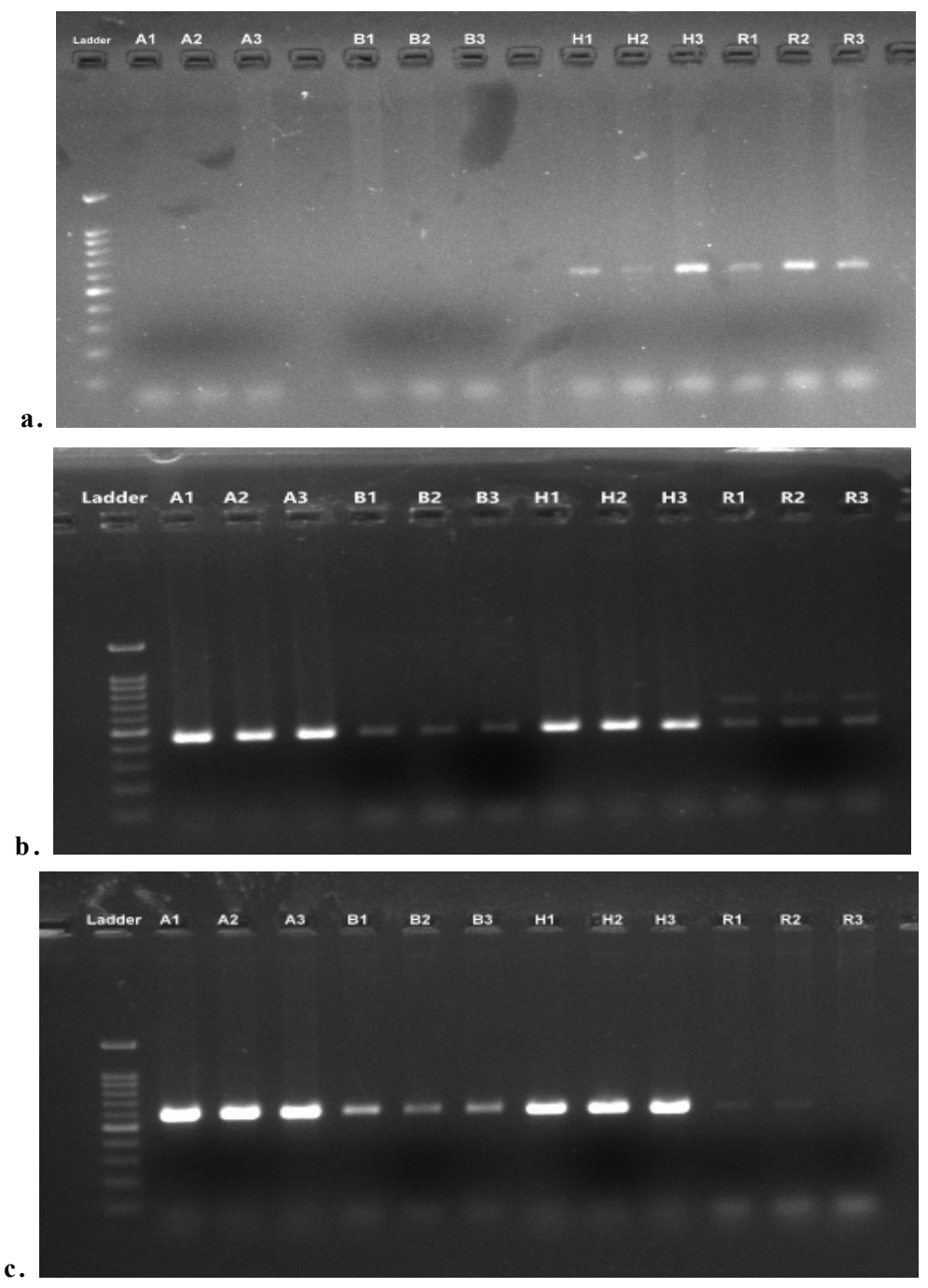

Fig 2: Characterization of parental lines and hybrid using SCAR markers; a. CRF-SCAR 870 at 600 bp, b. atp6-SCAR at 450 bp and c. orf-456-SCAR at 600 bp. A line $=A 1$ to $A 3, B$ line $=B 1$ to B3, Hybrid = H1 to H3 and R line = R1 to R3, Ladder= $100 \mathrm{bp}$.

\section{CONCLUSION}

In present investigation, the hybridity of UARChH42 ( $\mathrm{JCH} 42)$ chilli hybrid is determined by any similarity in the banding pattern with any of its parent. Hybrid produced band in case of sterile cytoplasm specific markers viz., P1 and P2, coxllSCAR, CMS-SCAR 130/140 and CMS-SCAR 130 and also for fertility restoration marker CRF-SCAR 870. This proves that hybrid consists of genes from both the parents (JNA- 1 and BVC-42) and it is produced by crossing the stigma of JNA- 1 with pollen from BVC-42 in hybrid seed production programme. SCAR markers proved to be an effective marker system for the identification of parental lines and hybrid in case of this newly release CGMS based chilli hybrid.

\section{REFERENCES}

Anonymous, (2019). Selected State-wise Area, Production and Productivity of Dry Chillies in India (2015-16 and 2016-17). https://www.indiastat.com
Aulakh, P.S. (2016). Molecular mapping of nuclear male sterility gene ms10 in chilli pepper (Capsicum annuum L.) Ph.D. Thesis. Punjab Agricultural University, Ludhiana.

Budar, F., Touzet, P. and De, P.R. (2003). The nucleo-mitochondrial conflict in cytoplasmic male sterilities revisited. Genetica. 117: 3-16.

Chen, F., Zhu, S.W., Xiang, Y., Jiang, H.Y. (2010). Molecular markerassisted selection of the ae alleles in maize. Genetics and Mol. Res. 9: 1074-1084.

Dhaliwal, M.S. and Jindal, S.K. (2014). Induction and exploitation of nuclear and cytoplasmic male sterility in pepper (Capsicum spp.): A review. J. Hort. Sci. and Biotech. 89(5): 471-79.

Lin, S.W., Shieh, H.C., Wang, Y.W., Tan, C.W., Schafleitner, R., Yang, W.J. and Kumar, S. (2015). Restorer breeding in sweet pepper: Introgressing Rf allele from hot pepper through marker-assisted backcrossing. Scientia Horticulturae. 197: $170-75$. 
Mokate, A.S. (2009). Genetic analysis of CGMS based hybrids using newly identified fertility restorer lines and confirmation through molecular markers in chilli (Capsicum annuum L.). Thesis. Anand Agricultural University, Gujarat, India. Oland, M.L. and Porter, A.M. (1941). A study of natural crossing in peppers, Capsicum frutesences. Proc. Am. Soc. Horticulture Sci. 38: 585-588.

Paran, I. and Michelmore, R.W. (1993). Development of reliable PCR-based markers linked to downy mildew resistance genes in lettuce. Theoretical and Appl. Genetics. 85(8): 985-93.

Schnable, P.S. and Wise, R.P. (1998). The molecular basis of cytoplasmic male sterility and fertility restoration. Trends in Plant Sci. 3: 175-180.
Sun, G.S., Dai, Z.L., Bosland, P.W., Wang, Q., Sun, C.Q., Zhang, Z.C. and Ma, Z.H. (2017). Characterizing and markerassisting a novel chili pepper (Capsicum annuum L.) yellow bud mutant with cytoplasmic male sterility. Genetic and Mol. Res. 16(1): 1-11.

Tembhurne, B.V., Babu, K., Gurumurthi, N.K., Biradar, V., Biradar, B. and Lokesha, R. (2016). Molecular characterization of CMS lines and standardization of hybrid seed production technique in chilli (Capsicum annuum L.). J. Agricultural Sci. and Technol. 6: 238-243.

Yeh, T., Lin, S., Shieh, H., Teoh, Y. and Kumar, S. (2016). Markers for cytoplasmic male sterility (CMS) traits in chilli peppers (Capsicum annuum L.). I: multiplex PCR and validation, SABRAO. J. Breed. and Genetics. 48(4): 465-73. 